\title{
Bromine and bromide content in soils: Analytical approach from total reflection X-
} ray spectrometry

\author{
Helena Gallardo, ${ }^{\mathrm{a}}$ Ignasi Queralt, ${ }^{\mathrm{a}, \mathrm{b}}$ Josefina Tapias, ${ }^{\mathrm{c}}$ Lucila Candela, ${ }^{\mathrm{d}}$ Eva Margui ${ }^{\mathrm{e}, *}$ \\ a Institute of Earth Sciences Jaume Almera, CSIC, Sole Sabaris s/n, 08028, Barcelona, Spain \\ ${ }^{\mathrm{b}}$ Institute of Environmental Assessment and Water Research, CSIC, Jordi Girona 18-26, 08034, Barcelona, Spain \\ ${ }^{c}$ Department of Natural Products, Plant Biology and Soil Science, University of Barcelona, Joan XXIII 27-31, 08028, Barcelona, Spain \\ d Department of Geotechnical Engineering and Geoscience, Technical Univ. of Catalonia-UPC, Gran Capitan s.n., 08034, Barcelona, Spain \\ e Department of Chemistry, University of Girona, Campus Montilivi s/n, 17071, Girona, Spain
}

\section{A R T I C L E IN F O}

Article history:

Received 1 October 2015

Received in revised form 23 April 2016

Accepted 30 April 2016

Available online $\mathrm{xxx}$

Handling Editor: Andreas Sjodin

\section{Keywords:}

Bromine

Bromide

TXRF

Soil

\section{A B S T R A C T}

Monitoring total bromine and bromide concentrations in soils is significant in many environmental studies. Thus fast analytical methodologies that entail simple sample preparation and low-cost analyses are desired.

In the present work, the possibilities and drawbacks of low-power total reflection X-ray fluorescence spectrometry (TXRF) for the determination of total bromine and bromide contents in soils were evaluated.

The direct analysis of a solid suspension using $20 \mathrm{mg}$ of fine ground soil $(<63 \mu \mathrm{m})$ gave a $3.7 \mathrm{mg} \mathrm{kg}^{-1}$ limit of detection for bromine which, in most cases, was suitable for monitoring total bromine content in soils $(\mathrm{Br}$ content range in soils $=5-40 \mathrm{mg} \mathrm{kg}^{-1}$ ). Information about bromide determination in soils is also possible by analyzing the $\mathrm{Br}$ content in water soil extracts. In this case, the TXRF analysis can be directly performed by depositing $10 \mu \mathrm{L}$ of the internal standardized soil extract sample on a quartz glass reflector in a measuring time of $1500 \mathrm{~s}$. The bromide limit of detection by this approach was $10 \mu \mathrm{g} \mathrm{L}$.

Good agreement was obtained between the TXRF results for the total bromine and bromide determinations in soils and those obtained by other popular analytical techniques, e.g. energy dispersive X-ray fluorescence spectrometry (total bromine) and ionic chromatography (bromide).

As a study case, the TXRF method was applied to study bromine accumulation in two agricultural soils fumigated with a methyl bromide pesticide and irrigated with regenerated waste water.

(C) 2016 Published by Elsevier Ltd.

\section{Introduction}

Monitoring total bromine and bromide concentrations in soils is significant in many field and laboratory environmental studies. For instance, bromide and chloride ions have been widely used as tracers to study water and solute transport along soil's non saturated zone because they do not adsorb to negatively charged soil minerals. As bromide occurs in much smaller background concentrations in soils than chloride, it is often preferred as a tracer in transport studies (Bero et al., 2015, Dusek et al., 2015). Other anthropogenic sources of bromine include agricultural fumigations using methyl bromide (MB) to control soil-borne pathogens, nematodes and weeds in many vegetable, fruit, nut and nursery crops worldwide (Klose and Ajwa, 2004). Despite the fact that MB was phased out in 2010 (European Community, 2009), high concentrations levels of $\mathrm{Br}$ are still found in some agricultural soils. Finally, the use of salty or regenerated waters for irrigation has promoted Br enrichment of surface layers of soils (Queralt et al., 2012). Given all these applications, fast analytical methodologies to monitor both bromine and bromide in soils are desired.

Total bromine content in soil samples is usually determined by solid-state techniques such as instrumental neutron activation analy-

\footnotetext{
* Corresponding author.

Email address: eva.margui@udg.edu (E. Margui)
}

sis (INAA) (Muhammad et al., 2012) and X-ray fluorescence spectrometry (XRF) (Sandeep et al., 2014). Despite the high selectivity and sensitivity of INAA, expensive costs, the need for a nuclear reactor for irradiation, and the rather long analysis times imposed by long waiting (cooling) periods for short-lived radioisotopes to decay have restricted its application in some environmental studies. XRF, however, is a popular technique for major elemental analyses in geological samples as it helps avoid complicated acid-digestion procedures. In particular, the speed, accuracy and versatility of XRF are the most important features, among others, that have rendered it a very mature analytical tool in this field. For instance, the fast and direct wavelength dispersive XRF (WDXRF) analysis of total bromine in soil samples from the vadose zone has been successfully applied (Abderrahim et al., 2011) to estimate flux and transport along the unsaturated zone.

Some other analytical techniques have been used for the specific determination of bromide ions in soils (Crompton, 2012). In them all, bromide is first extracted from soil by a 24-h batch extraction procedure with deionised water (ASTM methods D4646-87, D5233-92 and D3987-85). The United States Environmental Protection Agency (US-EPA) proposes a potentiometric determination of bromide in the resulting soil extract using an ion-selective electrode (EPA Method $9211,1996)$. Ionic chromatography (IC) has also been widely used to determine bromide ion in aqueous samples. One of the benefits of this technique is the possibility of obtaining simultaneous information 
about the different anions present in the target sample (Tirumalesh, 2008). However, it is a relatively expensive analytical tool. Other less used methods for bromide determination in soil extracts include flow injection potentiometry (Van Staden, 1987) and indirect determinations by a spectrophotometry method (Miller and Angui, 1991).

In the present work, we explored the analytical possibilities of total reflection X-ray fluorescence spectrometry (TXRF) for the determination of total bromine and bromide contents in soils. TXRF is a well-established analytical technique for multielement determinations in various sample types, especially liquids and powdered or microsamples (Streli, 2006). To perform analyses under total reflection conditions, samples must be provided as thin films. This is done by depositing 5-50 $\mu \mathrm{L}$ of sample on a reflective carrier and subsequently drying the drop. As X-ray photons are totally reflected at very low glancing angles of the primary X-ray beam $\left(\sim 0.1^{\circ}\right)$ with the TXRF system and, thus, the high background that would generally occur due to scatter from the sample support is absent, limits of detection (LODs) are better than in conventional XRF systems (Marguí and Van Grieken, 2009). In recent decades, most published TXRF analyses have been performed using large-scale instruments with high-power X-ray tubes, which demand water-cooling systems and liquid-nitrogen cooled detectors. In recent years, the development and commercialization of bench top TXRF instrumentation, which offers extremely simple operations with a low-cost compact design, have promoted its application in many environmental fields (Stosnach, 2005; Floor et al., 2013) and also in water quality control studies (Marguí et al., 2010a, 2010b).

After bearing in mind the possibility of analyzing solid suspension by TXRF, the application of this technique was studied for total $\mathrm{Br}$ determination in soils, and to also determine bromine in soil extracts. To our knowledge, very few papers about TXRF investigations of geological samples exist, and there are none for $\mathrm{Br}$ determination in soils.

First, an evaluation of the best sample preparation and TXRF measurement conditions for $\mathrm{Br}$ determination in soils and soil extracts was made. The analytical figures of merit (LODs, accuracy and precision of results) for both methodologies (total $\mathrm{Br}$ and bromide determinations) were evaluated. The obtained TXRF results were compared with those obtained by other popular analytical techniques, e.g. energy dispersive XRF (total bromine) and IC (bromide). Finally as a study case, the TXRF method was applied to study bromine accumulation in two agricultural soils fumigated with a methyl bromide pesticide and irrigated with treated wastewater.

\section{Experimental}

\subsection{Materials and reagents}

A bromide stock solution of $1000 \mathrm{mg} \mathrm{L}^{-1}$ was prepared from analytical grade $\mathrm{NaBr}$ salt (Sigma-Aldrich, Spain). An Rh stock solution of $1000 \pm 0.5 \mu \mathrm{g} \mathrm{mL}^{-1}$ (Spectroscan, TECKNOLAB A/S, Norway) was used to standardize soil samples and soil extracts. The high purity water used for diluting stock solutions was obtained from a Milli-Q purifier system, which operated at 18.2 M $\Omega$ (Millipore Corp., Bedrod, MA). The commercial non ionic detergent Triton ${ }^{\circledR} \mathrm{X}-110$ was purchased from Sigma-Aldrich (Spain). In the TXRF analysis the sample carrier plays an important role in achieving optimal analytical results. In most cases, the reflective sample carrier is made of quartz or acrylic glass. In this work, quartz glass discs (diameter of $30 \mathrm{~mm}$ and thickness of $3 \mathrm{~mm} \pm 0.1 \mathrm{~mm}$; Bruker Nano $\mathrm{GmbH}$, Germany) were used as sample holders to introduce the sample into the TXRF equipment because of greater resistance to temperature and a lower background.

\subsection{Samples}

Two different agricultural soils were studied, taken from greenhouse cropped plots located in the alluvial plain of the Tordera river (40 km north of Barcelona, Spain). These soils have been treated with methyl bromide for the last 20 years and irrigated with treated wastewater. Incremental depth sampling (up to approx. $0.5 \mathrm{~m}$, maximum yearly plough depth) in 5-10 cm lengths was carried out with a manual Eijkelkamp hand-auger sampler. After air drying, samples were passed through a $0.250-\mathrm{mm}$ sieve and then ground in an agate mortar to pass through a $63-\mu \mathrm{m}$ sieve (see Section 3.1.3).

Several certified reference materials were employed to test the accuracy of the developed TXRF methodology for bromide determination: LKSD1-LKSD4 ("Lake sediment samples" from Natural Resources of Canada, Government of Canada), SO1-SO4 ("Soil samples" from CANMET Energy, Mines and Resources Canada), NCSDC73309 ("Stream sediment" from China National Analysis Centre for Iron and Steel), STSD-1, STSD-3 and STSD-4 ("Stream sediment" from Canadian Reference Material Project (CCRMP)).

\subsection{Total bromine determination in soil suspensions}

The best sample preparation conditions for soil suspensions analysers by TXRF were carefully evaluated (see Section 3.1.1). Finally, the conditions selected for the soil suspension analysis were as follows: $20 \mathrm{mg}$ of soil were suspended in $1 \mathrm{~mL}$ of the dispersant solution ( $1 \%$ Triton ${ }^{\circledR} \mathrm{X}-110$ in water). Then Rh was added to the slurry sample for internal standardization (final Rh concentration of $15 \mathrm{mg} \mathrm{kg}^{-1}$ ). Next the resulting solution was thoroughly homogenized (Vortex device) and an aliquot of $10 \mu \mathrm{L}$ was transferred to a quartz glass sample carrier and left to dry under an IR lamp before the TXRF analysis.

\subsection{Bromide determination in soil extracts}

After the pretreatment, $1 \mathrm{~g}$ of soil (sieved at $0.125 \mathrm{~mm}$ ) came into contact with $25 \mathrm{~mL}$ of MilliQ water (1:25 ratio). After $24 \mathrm{~h}$ of equilibration, the extract solutions were filtered $(0.2 \mu \mathrm{m}$ cellulose acetate filter) before the TXRF and IC analyses (Abderrahim et al., 2011).

The best sample preparation conditions for the soil extract analysis by TXRF were carefully evaluated (see Section 3.2.1). Briefly, an aliquot of $1 \mathrm{~mL}$ of soil was standardized using an adequate volume of $\mathrm{Rh}$ (final $\mathrm{Rh}$ concentration of $0.5 \mathrm{mg} \mathrm{kg}^{-1}$ ). Then the resulting solution was thoroughly homogenized (Vortex device) and an aliquot of $10 \mu \mathrm{L}$ was transferred to a quartz glass sample carrier and left to dry under an IR lamp before the TXRF analysis.

\subsection{Instrumental conditions}

Analyses of soil suspensions and extracts were performed with a commercial benchtop TXRF system, equipped with a low-power W X-ray tube (S2 PICOFOX, Bruker AXS Microanalysis GmBH, Berlin, Germany) that operated at $50 \mathrm{kV}$ and $1 \mathrm{~mA}$. In order to compare the obtained TXRF results for the soil suspension and soil extract analyses, a benchtop EDXRF system (S2 RANGER, Bruker AXS, GmbH, Germany), under the same conditions of voltage, current and detector as those for TXRF, and an Ion Chromatograph (IC5000, Dionex, Thermo Scientific, Inc., Spain), were respectively 
used. The instrument specifications and final measurement conditions used for TXRF, EDXRF and IC are summarized in Table 1.

\subsection{Quantification by TXRF}

For TXRF, quantification can be performed directly by internal standardization (external calibration is not needed). This method is based on the addition of an element, named the internal standard (IS), which is not present in the sample (see Expression 1):

$$
\mathrm{C}_{\mathrm{i}}=\frac{\left(\mathrm{N}_{\mathrm{i}} \mathrm{C}_{\mathrm{pi}} \mathrm{S}_{\mathrm{pi}}\right)}{\left(\mathrm{N}_{\mathrm{pi}} \mathrm{S}_{\mathrm{i}}\right)}
$$

where $C_{i}$ is the analyte concentration, $N_{i}$ is the analyte net peak area, $\mathrm{C}_{\mathrm{pi}}$ is the IS concentration, $\mathrm{S}_{\mathrm{pi}}$ is the instrumental sensitivity for IS, $\mathrm{N}_{\mathrm{pi}}$ is the IS net peak area and $S_{i}$ is the instrumental sensitivity for the analyte.

Medium-heavy elements with $\mathrm{K}$ lines detection are preferred for use as internal standards over heavy elements with $\mathrm{L}$ lines detection due to the lower number of peaks. Lighter elements with $Z \leq 21$ are not suitable as standards because of particle size-effects that are problematic within a low-energy range $E<4 \mathrm{keV}$ (Klockenkämper and Von Bohlen, 2015). Appreciable amounts of Ga and Y were found in the analysis of the target soil samples. Therefore, these elements, which are commonly used in TXRF analyses as internal standards, could not be employed, which is why Rh was finally selected as the internal standard.

For both soil suspension and extracts, a measuring time of $1500 \mathrm{~s}$ was selected as a trade off between an acceptable repetitiveness of the results $(\mathrm{RSD} \sim 6 \%)$ and the total analysis time.

Table 1

Instrumental parameters and measurement conditions.

\begin{tabular}{|c|c|}
\hline \multicolumn{2}{|c|}{ TXRF benchtop spectrometer (S2 PICOFOX, Bruker AXS) } \\
\hline X-Ray tube & $\mathrm{W}$ \\
\hline Rating & $50 \mathrm{kV}, 1 \mathrm{~mA}$ (maximum power $50 \mathrm{~W}$ ) \\
\hline Optics & Multilayer Ni/C, $17.5 \mathrm{keV}, 80 \%$ reflectivity \\
\hline Detector & $\begin{array}{l}\text { XFLASH }{ }^{\text {TM }} \text { Si drift detector, } 10 \mathrm{~mm}^{2},<160 \mathrm{eV} \text { resolution } \\
\mathrm{Mn}-\mathrm{K}_{\alpha}\end{array}$ \\
\hline $\begin{array}{l}\text { Working } \\
\text { environment }\end{array}$ & Air \\
\hline Sample station & Cassette changer for 25 samples \\
\hline Size, weight & $600 \times 300 \times 450 \mathrm{~mm}, 37 \mathrm{~kg}$ \\
\hline Measurement time & $1500 \mathrm{~s}$ \\
\hline \multicolumn{2}{|c|}{ EDXRF benchtop spectrometer (S2 Ranger, Bruker AXS) } \\
\hline X-ray tube & $\mathrm{Pd}$ \\
\hline Rating & $50 \mathrm{kV}, 1 \mathrm{~mA}$ (maximum power $50 \mathrm{~W}$ ) \\
\hline Primary filter & $\mathrm{Al} 500 \mu \mathrm{m}$ \\
\hline Detector & $\begin{array}{l}\text { XFLASH }{ }^{\text {TM }} \text { Silicon Drift Detector, }<129 \text { eV resolution Mn- } \\
\mathrm{K}_{\alpha}\end{array}$ \\
\hline $\begin{array}{l}\text { Working } \\
\text { environment }\end{array}$ & Vacuum \\
\hline Measurement time & $300 \mathrm{~s}$ \\
\hline \multicolumn{2}{|c|}{ Ion chromatograph (IC5000, Dionex) } \\
\hline Column & $\begin{array}{l}\text { IonPac }{ }^{\circledR} \text { AS18 anion-exchange column }(4 \times 250 \mathrm{~mm}) \text { with } \\
\text { the AG Guard column }(4 \times 50 \mathrm{~mm})\end{array}$ \\
\hline Eluent flow rate & $1 \mathrm{~mL} / \mathrm{min}$ \\
\hline Injection volume & $25 \mu \mathrm{L}$ \\
\hline Detector & Conductivity detector (suppressed conductivity) \\
\hline $\begin{array}{l}\text { Eluent generation of } \\
\text { mobile phase }\end{array}$ & $22-40 \mathrm{mM} \mathrm{KOH}$ \\
\hline Data system & Chromeleon 6.8 \\
\hline
\end{tabular}

\section{Results and discussion}

\subsection{Analysis of soil suspensions}

\subsubsection{Selecting the sample preparation strategy for soil suspension analyses}

One of the most interesting features of TXRF in the analytical field is the possibility of the quantitative direct analysis of solid samples with no prior chemical treatment. A direct solid analysis can be accomplished by means of adequate suspension, followed by internal standardization.

In the present work, a study of the best sample preparation strategy for Br determination in soil suspensions was conducted. Experimental tests were performed by analyzing the certified reference material LKSD-4 ([Br] $\left.=49 \mathrm{mg} \mathrm{kg}^{-1}\right)$. Two dispersant agents (MilliQ water, $1 \%$ Triton ${ }^{\circledR} \mathrm{X}-114$ in water) and different amounts of sample were tested for soil suspension preparation. As seen in Fig. 1A, the best results were obtained by suspending $20 \mathrm{mg}$ of soil sample in $1 \mathrm{~mL}$ of $1 \%$ Triton ${ }^{\circledR} \mathrm{X}-114$ in water.

The aim of the sample preparation process in TXRF is to obtain the target sample as a thin layer $(<100 \mu \mathrm{m})$ on a carrier with a high reflectivity sample support. Therefore, the choice of an adequate sample deposition volume is crucially important to obtain a thin layer and to ensure the total reflection conditions. The influence of the suspension deposition volume $(5 \mu \mathrm{L}, 5+5 \mu \mathrm{L}, 10 \mu \mathrm{L}, 20 \mu \mathrm{L})$ on the $\mathrm{Br}$ content determination is shown In Fig. 1B. In view of the obtained results, a volume of $10 \mu \mathrm{L}$ was established for further experiments.

\subsubsection{Analytical figures of merit}

The LOD (calculated using Expression 2) for Br was $3.7 \mathrm{mg} \mathrm{kg}^{-1}$ when using the best analytical conditions studied to prepare the suspension.

$$
L O D=\frac{3 \mathrm{C}_{\mathrm{i}} \sqrt{\mathrm{N}_{\mathrm{bkg}}}}{\mathrm{N}_{\mathrm{i}}}
$$

where $C_{i}$ is the concentration of a given analyte, $N_{b k g}$ is the background area and $\mathrm{N}_{\mathrm{i}}$ is the net area of the analyte. This equation is analogous to the $3 \sigma$ definition of the LOD.

Therefore, this fast and relatively simple methodology can be successfully applied to analyze $\mathrm{Br}$ content in most soils by taking into account that the bromine content range in soils is $5-40 \mathrm{mg} \mathrm{kg}^{-1}$ (Reimann and De Caritat, 1998). In order to check the accuracy of the method, different certified reference materials were analyzed under the above-described analytical conditions (see Table 2 for the results). As we can see, a good agreement with the certified/indicative values was generally achieved over the whole studied concentration range. Global precision was also tested by analyzing eight replicates of the certified reference material LKSD-4 $\left([\mathrm{Br}]=49 \mathrm{mg} \mathrm{kg}^{-1}\right)$. The calculated relative standard deviation (RSD), with a value of $6 \%$, was acceptable.

\subsubsection{Effect of soil particle size}

It has been demonstrated that the appearance of microscopic mountain agglomeration effects when depositing the sample on the reflector can result in large deviations in the nominal TXRF result values (Fernández-Ruiz, 2009). Agglomeration effects in TXRF analyses of solid samples are related to solid particle size. Therefore, studying the solid sample particle size effect is highly recommended 


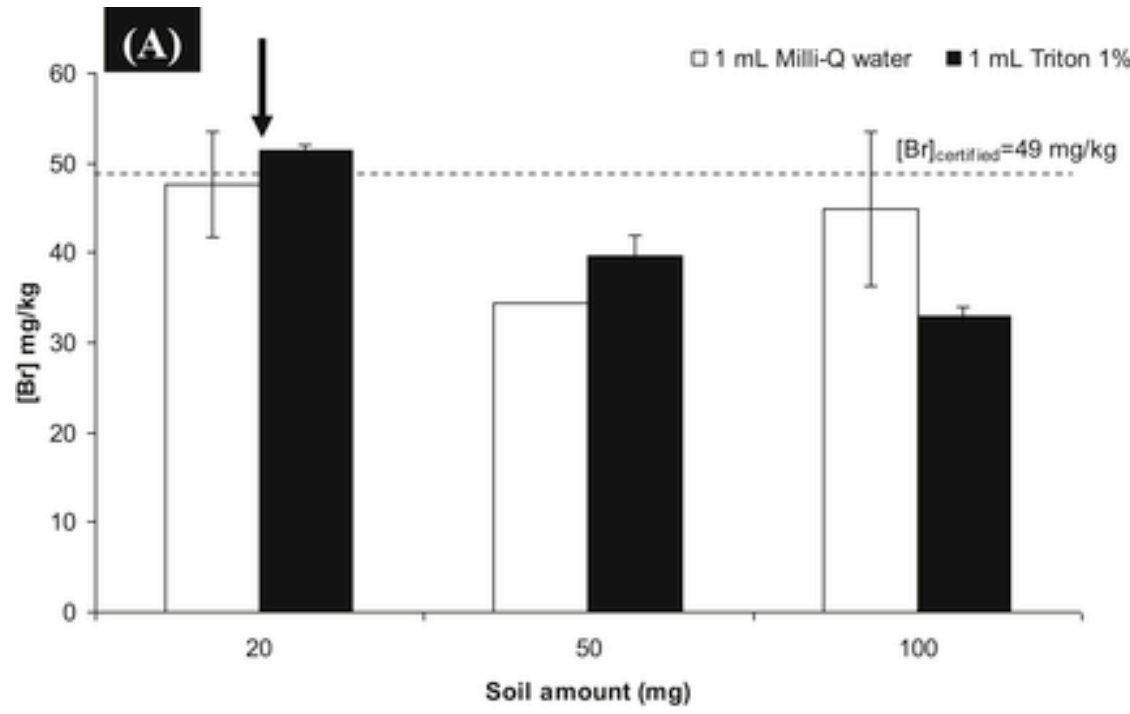

(B)

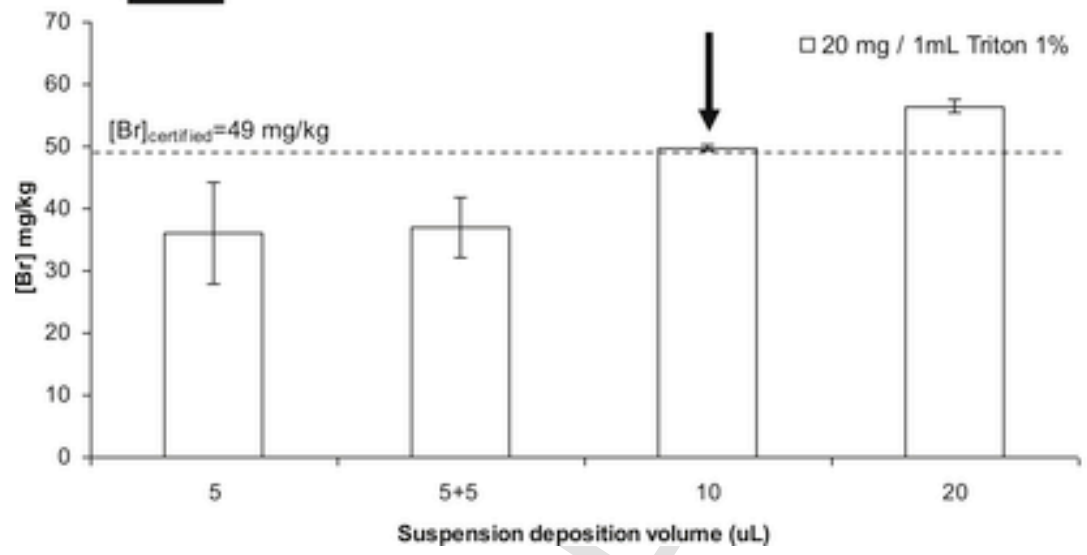

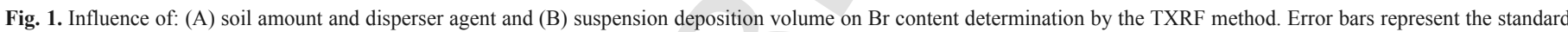
deviation of two replicates. Arrow indicates best sample preparation conditions.

Table 2

Br concentrations $\left(\mathrm{mg} \mathrm{kg}^{-1}\right)$ in the certified reference materials after suspension sample preparation and a subsequent TXRF analysis (analytical conditions: $20 \mathrm{mg}$ of sample, $1 \mathrm{~mL}$ of Triton $1 \%$, sample deposition volume: $10 \mu \mathrm{L}, 1500 \mathrm{~s}$ measuring time).

\begin{tabular}{llll}
\hline Sample & \multicolumn{2}{l}{ Solid suspension TXRF method } & Certified \\
\hline & Mean $(\mathrm{n}=2)$ & SD $(\mathrm{n}=2)$ & \\
\hline LKSD1 & 13.1 & 0.1 & 11 \\
LKSD2 & 16 & 2 & 18 \\
LKSD3 & 15.7 & 0.2 & 16 \\
LKSD4 & 51 & 2 & 49 \\
SO-1 & n.d & n.d & 2 \\
SO-2 & 22 & 2 & 17 \\
SO-3 & 8 & 0.3 & 6 \\
SO-4 & 5.6 & 0.2 & 5.2 \\
NCSDC73309 & n.d & n.d & 2.2 \\
STSD-1 & 45 & 2 & 40 \\
STSD-3 & 26.6 & 0.4 & 24 \\
STSD-4 & 15 & 3 & 13 \\
\hline
\end{tabular}

n.d: not detected.

when analyzing solid samples by TXRF using suspension preparation. Usually, the particle size of soil and sediment certified reference materials is lower than $70 \mu \mathrm{m}$. At this particle size level, sample suspension homogeneity is acceptable and the TXRF results are not biased (see Table 2).

In order to study the influence of particle size on $\mathrm{Br}$ determination in real soil samples, six soils samples of different particle sizes were prepared as suspensions and analyzed following the procedure described in Section 2.2. The obtained $\mathrm{Br}$ results were compared with those obtained by energy dispersive X-ray spectrometry. As shown in Fig. 2, particle size greatly affects the $\mathrm{Br}$ concentration determined by the proposed TXRF methodology. The obtained results indicated that soil particle size had to be reduced from $125 \mu \mathrm{m}$ to $63 \mu \mathrm{m}$ in order to obtain statistically similar values compared to the EDXRF ones.

\subsubsection{Application to total bromine determinations in agricultural soils}

By taking into account the expected $\mathrm{Br}$ levels in the two target agricultural soil profiles, soil suspension was selected as sample treatment before the TXRF analysis. Fig. 3 illustrates the Br concentrations obtained according to depth for the two target soils; in both cases, the $\mathrm{Br}$ concentrations in upper soil layers (up to $30 \mathrm{~cm}$ ) are significantly higher than those obtained when analyzing deeper layers. This fact can be related to the repeated use of methyl bromide as a 


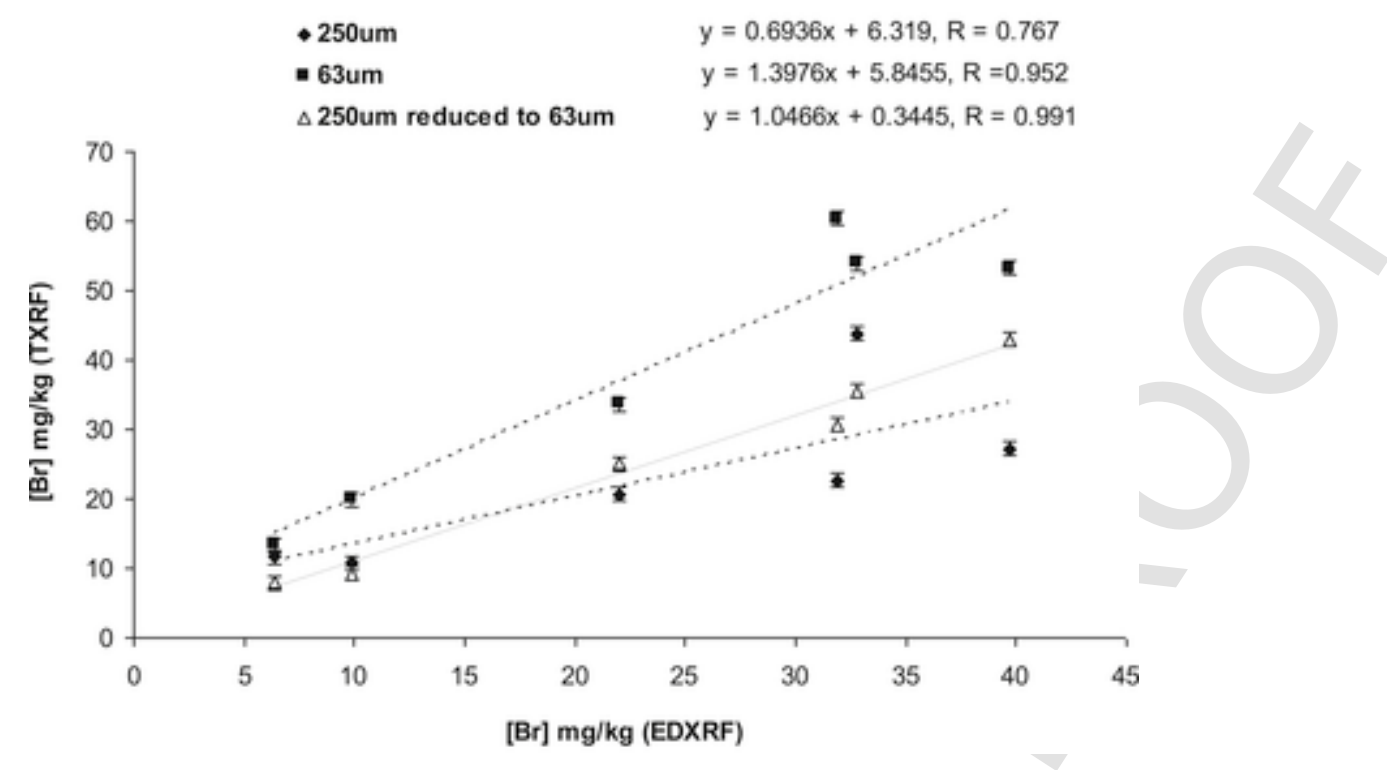

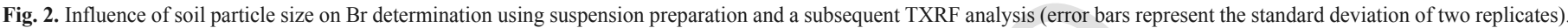
Sample preparation for the EDXRF analysis consists of a powdered pellet ( $10 \mathrm{~g}$ soil ground to pass through a 0.250 -mm sieve $+0.8 \mathrm{~g}$ Elvacite as the binding agent).

\section{$[\mathrm{Br}] \mathrm{mg} / \mathrm{kg}$}

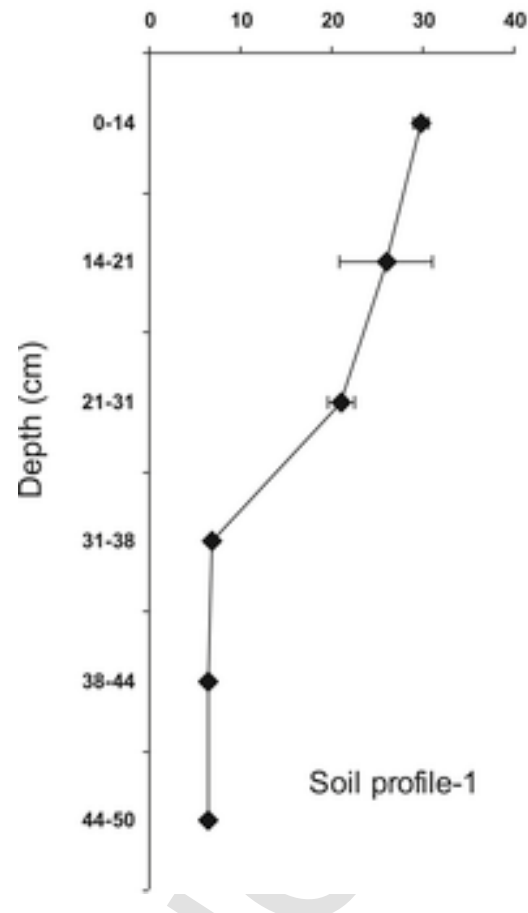

$[\mathrm{Br}] \mathrm{mg} / \mathrm{kg}$

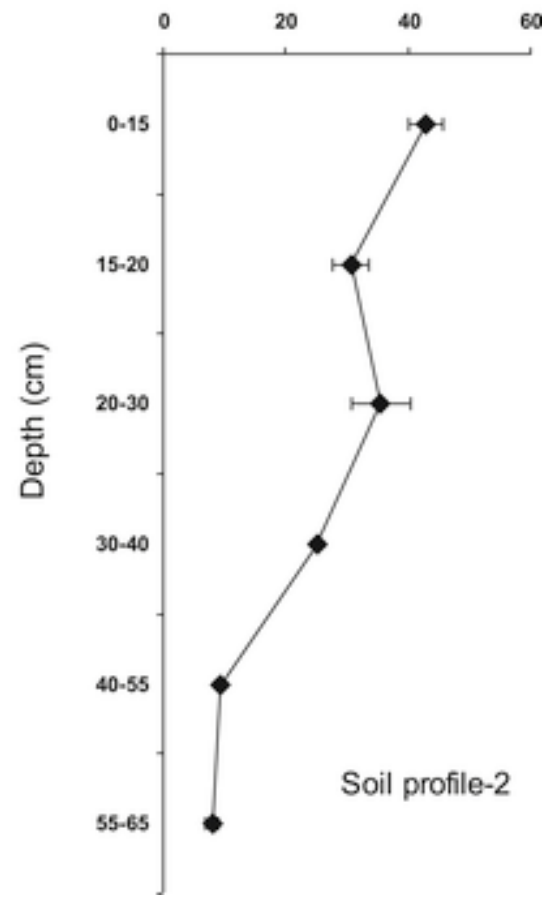

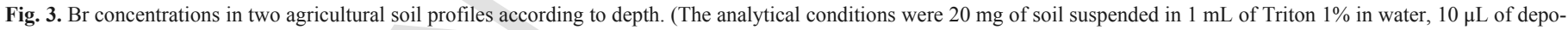
sition volume, $1500 \mathrm{~s}$ measuring time).

pesticide, and also to the use of treated wastewater for irrigation purposes. As previously pointed by Zaccone et al., (2008), Br has a high affinity to organic matter, which usually accumulates in upper layers of agricultural soils.

By way of example, the TXRF spectrum obtained for one of the surface soil samples $(0-15 \mathrm{~cm}$, Soil profile-2) is displayed in Fig. 4. An examination of the X-ray fluorescence lines revealed that the characteristic $\mathrm{Br}$ line $\left(\mathrm{Br}-\mathrm{K}_{\alpha}\right)$ clearly resolved, and no other element peaks from the soil matrix overlapped the analyte peak. As shown in Fig. 4, a clear advantage of the TXRF analyses is that multielemental information about the soil sample can be obtained. Therefore in addition to $\mathrm{Br}$ determination, direct measurements of soil slurries can be applied to also obtain a rough overview of soil composition. 


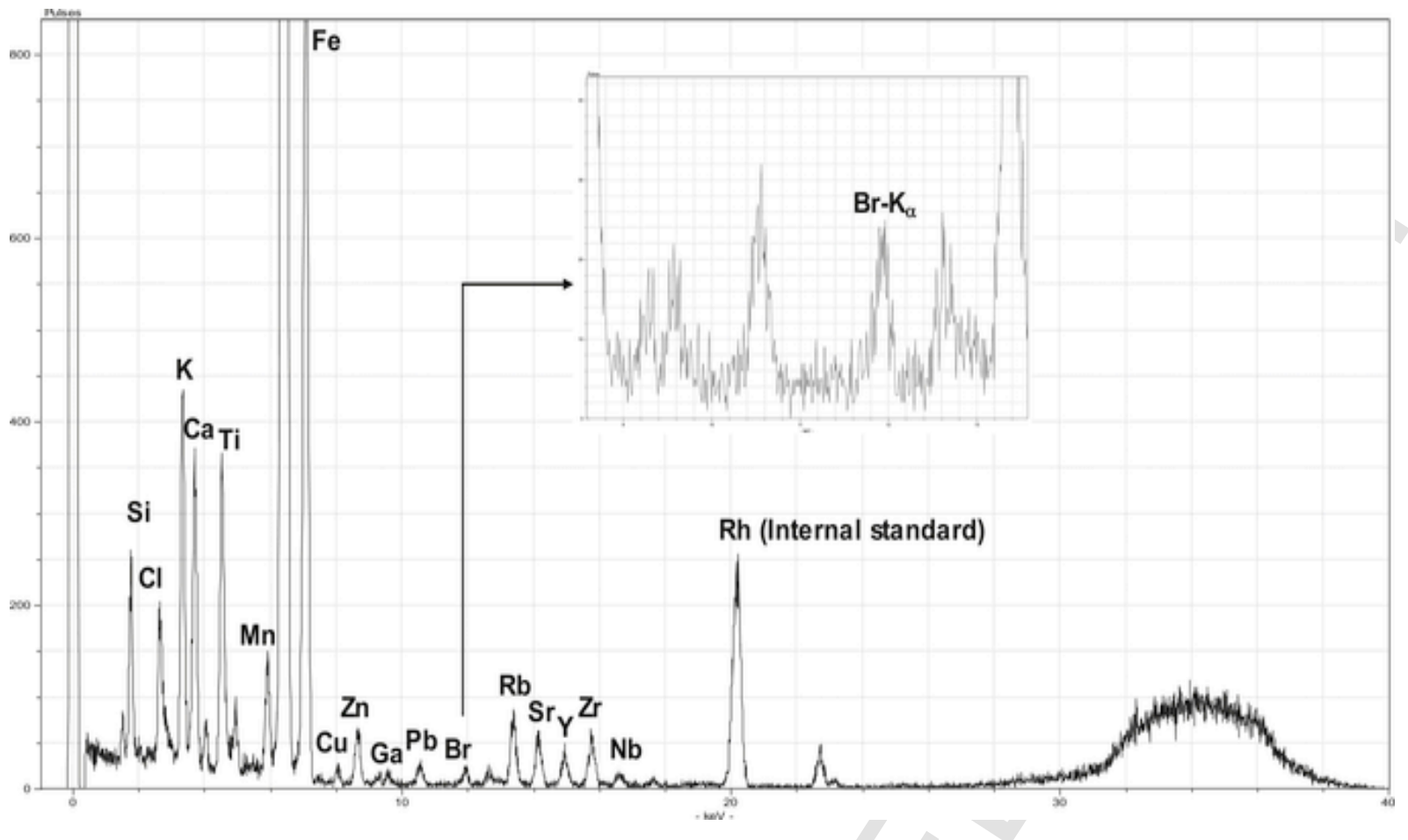

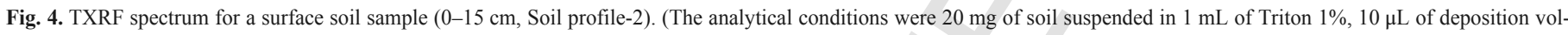
ume, $1500 \mathrm{~s}$ measuring time).

\subsection{Analysis of soil extracts}

An evaluation of the possibilities of TXRF to determine $\mathrm{Br}$ in soil extracts was made. Bromide extraction was based on the procedure usually employed for determining bromide by ionic chromatography (see the details in Section 2.3).

\subsubsection{Selection of the sample preparation strategy for soil extract analyses}

For soil extracts, the influence of the sample deposited volume on $\mathrm{Br}$ determination was studied. To this end, different sample volumes (from 5 to $40 \mu \mathrm{L}$ ) of a soil extract that contained $500 \mu \mathrm{g} \mathrm{L}^{-1}$ of $\mathrm{Br}$ (corresponding to $12.5 \mathrm{mg} \mathrm{kg}^{-1}$ of $\mathrm{Br}$ in soil) were analyzed using the best previously reported conditions. In view of the obtained results, a sample deposition volume of $10 \mu \mathrm{L}$ was selected since sensitivity was higher and the deviation between replicates was lower compared to other tested volumes (for details, see Fig. 1 in the Supporting Information).

\subsubsection{Analytical figures of merit}

The LODs for $\mathrm{Br}$ in soil extracts were also calculated (using Expression 2) by analyzing a soil extract that contained $500 \mu \mathrm{g} \mathrm{L}^{-1}$ of $\mathrm{Br}$. The LOD for Br was around $10 \mu \mathrm{g} \mathrm{L}^{-1}$, which corresponded to $0.25 \mathrm{mg} \mathrm{kg}^{-1}$ of $\mathrm{Br}$ in soil. Therefore, the LOD for Br determination in soil extracts was around 15-fold lower compared to that obtained for the direct soil suspension analysis. This fact can be related with a lower background compared to a solid sample analysis.

In order to study the applicable $\mathrm{Br}$ concentration range, several soil extracts were spiked at different bromide concentration levels (from 50 to $500 \mu \mathrm{g} \mathrm{L}^{-1}$, which corresponded to $1.25-12.5 \mathrm{mg} \mathrm{kg}^{-1}$ of $\mathrm{Br}$ in soil) and analyzed by the proposed TXRF method. As shown in Fig. 5, a clear linear relationship is seen between the real bromide

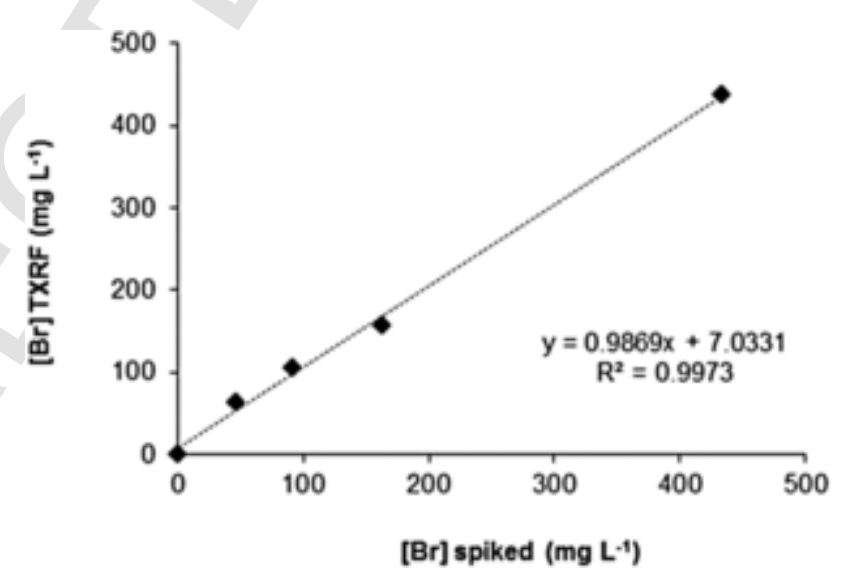

Fig. 5. TXRF Br concentration vs. bromide concentration for the spiked soil extract samples at different concentration levels.

concentration in the extract and the Br concentration obtained by the TXRF method. No statistical differences were found at the $95 \%$ confidence level.

Finally, the TXRF method was applied to determine $\mathrm{Br}$ content in two real soil extracts. The obtained results were compared with those obtained by ionic chromatography (the reference technique). As the results display in Table 3 show, the $\mathrm{Br}$ concentrations determined by the two methods are in good agreement. No significant differences were found at the $95 \%$ confidence level.

Global precision was also tested by analyzing five different soil extracts of the same soil sample (containing $500 \mu \mathrm{g} \mathrm{L}^{-1}$ of $\mathrm{Br}$ ) and the calculated RSD was around $11 \%$. In order to estimate the uncertainty associated with the TXRF measurement, one of the soil extracts was measured 5 times. In this case the calculated RSD was 
Table 3

Comparison of the mean $\mathrm{Br}$ concentrations in the soil extracts analyzed by the TXRF method and by ion chromatography. Concentrations are expressed as $\mathrm{mg} \mathrm{kg}^{-1}$ with the relative standard deviation of two replicates.

\begin{tabular}{lccc}
\hline Sample & TXRF method & IC method & $\mathrm{t}_{\text {calc }}{ }^{\mathrm{a}}$ \\
\hline Extract soil-1 & $5.6 \pm 0.9$ & $5.0 \pm 0.2$ & 0.9 \\
Extract soil-2 & $10.3 \pm 0.8$ & $11.4 \pm 0.6$ & 1.6 \\
\hline
\end{tabular}

a Students " $t$ "-test. $\mathrm{t}_{\text {calc }}=$ calculated absolute value, $\mathrm{t}_{\text {critic }}=4.30(\mathrm{P}=0.05)$.

around $6 \%$, which indicated that a significant part of uncertainty was due to sample preparation (the $\mathrm{Br}$ extraction procedure).

\section{Conclusions}

This work demonstrated the possibilities of several analytical approaches combined with TXRF spectrometry for $\mathrm{Br}$ determination in soil.

The use of direct analysis of soil suspensions by TXRF can be an interesting, fast and relatively simple methodology to obtain total $\mathrm{Br}$ concentrations in soils, provided that $\mathrm{Br}$ content is higher than $4 \mathrm{mg} \mathrm{kg}^{-1}$. It can also be successfully applied to obtain a preliminary idea of the multielemental composition of soil. However, in order to obtain quality analytical results, it is mandatory to ensure that the soil particle size to prepare the soil suspension is lower than $63 \mu \mathrm{m}$. This method has been successfully applied to study bromine accumulation in two agricultural soils fumigated with methyl bromide pesticide and irrigated with treated waste water. It could also be interesting to extend this application to other soil types with similar bromine levels, such as soils in which bromine is used as a tracer (water transport along unsaturated zone studies).

The data presented herein also indicate the versatility of benchtop TXRF instrumentation for bromide determination in soil extracts. In this case, the TXRF analysis can be directly performed by depositing $10 \mu \mathrm{L}$ of the internal standardized soil extract sample on a quartz glass reflector in a measuring time of $1500 \mathrm{~s}$. The attained results are comparable to those obtained by ionic chromatography, which is the reference technique to monitor bromide in this type of samples.

To summarize, the TXRF methods proposed herein for bromine and bromide determinations entail less sample manipulation and smaller amounts of reagents compared with the most widespread techniques. Other advantages of the TXRF methods include the possibility of acquiring multielemental information about the sample, easy quantitation through internal standardization, and also low operating costs since the benchtop system does not require cooling media and gas consumption to operate.

\section{Acknowledgments}

This work was supported by Spanish National Research Programmes (Project ref. CGL2010-22168-C03-01 and Project ref. CGL2013-48802-C3-2-R). H. Gallardo gratefully acknowledges the Spanish Ministry of Economy and Competitiveness for the Research Staff Training Grant (FPI) with reference BES-2011-051348.

\section{Appendix A. Supplementary data}

Supplementary data related to this article can be found at http://dx. doi.org/10.1016/j.chemosphere.2016.04.136.

\section{Uncited references}

Belova et al., 2013; Quiao et al., 2015.

\section{References}

Abderrahim, H., Candela, L., Queralt, I., Tamoh, K., Maslouhi, A., 2011. X-ray fluorescence analysis for total bromine tracking in the Vadose Zone: results for Mnsara, Morocco. Vadose Zone J. 10, 1-5.

Belova, A., Narayan, T., Olkin, I., 2013. Methyl bromide alternatives for strawberry and tomato pre-plant uses: a meta-analysis. Crop Prot. 54, 1-14.

Bero, N.J., Ruark, M.D., Lowery, B., 2015. Bromide and chloride tracer application to determine sufficiency of plot size and well depth placement to capture preferential flow and solute leaching. Geoderma 262, 94-100.

Crompton, T.R., 2012. Determination of Anions: a Guide for the Analytical Chemist. Springer Science \& Business Media.

Dusek, J., Dohnal, M., Snehota, M., Sobotkova, M., Ray, C., Vogel, T., 2015. Transport of bromide and pesticides through an undisturbed soil column: a modeling study with global optimization analysis. J. Contam. Hydrol. 175-176, 1-16.

EPA Method 9211, December 1996. Potentiometric Determination of Bromide in Aqueous Samples with Ion-selective Electrode. United States Environmental Agency (USEPA).

European Community Management Strategy for the Phase-out of Critical Uses of Methyl Bromide, April 2009.. http://ozone.unep.org/Exemption_Information/Critical_use nominations_for_methyl_bromide/MeBr_Submissions/ EC\%20Management\%20 Strategy\%20for\%20Methyl\%20Bromide.pdf.

Fernández-Ruiz, R., 2009. Three empirical cases of the deposition morphology influence in the analytical quality of direct solid suspension measurements by total-reflection X-ray fluorescence. Spectrochim. Acta B 64, 672-678.

Floor, G.H., Marguí, E., Hidalgo, M., Queralt, I., Kregsamer, P., Streli, C., Román-Ross, G., 2013. Study of selenium sorption processes in volcanic ash using total reflection X-ray fluorescence (TXRF). Chem. Geol. 352, 19-26.

Klockenkämper, R., Von Bohlen, A., 2015. Total-reflection X-ray Fluorescence Analysis and Related Methods, second ed. John Wiley \& Sons, New Jersey.

Klose, S., Ajwa, H.A., 2004. Enzyme activities in agricultural soils fumigated with methyl bromide alternatives. Soil Biol. Biochem. 36, 1625-1635.

Marguí, E., Van Grieken, R., 2009. X-ray Fluorescence Spectrometry and Related Techniques: an Introduction. Momentum Press, Newyork.

Marguí, E., Tapias, J., Casas, A., Hidalgo, M., Queralt, I., 2010a. Analysis of inlet and outlet industrial wastewater effluents by means of benchtop total reflection X-ray fluorescence spectrometry. Chemosphere 80, 263-270.

Marguí, E., Kregsamer, P., Hidalgo, M., Tapias, J., Casas, A., Queralt, I., Streli, C., 2010 b. Analytical approaches for $\mathrm{Hg}$ determination in wastewater samples by means of total reflection X-ray fluorescence spectrometry. Talanta 82 (2), 821-827.

Miller, J.W., Angui, K.T.P., 1991. Indirect determination of bromide at trace levels in soil extracts. Soil Sci. Soc. Am. J. 55, 384-388.

Muhammad, B.G., Jaafar, M.S., Rahman, A.A., Ingawa, F.A., 2012. Determination of radioactive elements and heavy metals in sediments and soil from domestic water sources in northern peninsular Malaysia. Environ. Monit. Assess. 184, 5043-5049.

Queralt, I., Gallardo, H., Tapias, J., Margui, E., Candela, L., 2012. Energy dispersive Xray fluorescence analysis of total bromine in soils. In: Book of Abstracts. European Conference on X-ray Spectrometry. Viena, Austria. p. 276. PS2-57.

Quiao, K., Wang, Z., Wei, M., Wang, H., Wang, Y., Wang, K., 2015. Evaluation of chemical alternatives to methyl bromide in tomato crops in China. Crop Prot. 67, 223-227.

Reimann, C., De Caritat, P., 1998. Chemical Elements in the Environment. Factsheets for the Geochemist and Environmental Scientist. Springer-Verlag GmbH, Germany.

Sandeep, P., Kothai, P., Dusane, C.B., Sahu, S.K., Pandit, G.G., 2014. Determination of multi-element profiles of soil at Visakhapatnam using EDXRF technique. J. Radioanal. Nucl. Chem. 302, 1371-1376.

Stosnach, H., 2005. Environmental trace-element analysis using a benchtop total reflection X-ray fluorescence spectrometer. Anal. Sci. 21, 873-876.

Streli, C., 2006. Recent advances in TXRF. Appl. Spectrosc. Rev. 41, 473-489.

Tirumalesh, K., 2008. Simultaneous determination of bromide and nitrate in contaminated waters by ion chromatography using amperometry and absorbance detectors. Talanta $74,1428-1434$.

Van Staden, J.F., 1987. Flow injection determination of inorganic bromide in soils with a coated tubular solid-statebromide-selective electrode. Analyst 112, 595-599.

Zaccone, C., Cocozza, C., Shotyk, W., Miano, T.M., 2008. Humic acids role in Br accumulation along two ombrotrophic peat bog profiles. Geoderma 146, 26-31. 